\title{
Interactive property attribution in concept combination
}

\author{
ZACHARY ESTES and SAM GLUCKSBERG \\ Princeton University, Princeton, New Jersey
}

\begin{abstract}
We address the question of how people understand attributive noun-noun compounds. Alignment-andcomparison models suggest that the similarity of the constituent concepts guides interpretation. We propose, as an alternative, an interactive property attribution model wherein the modifier and head concepts have different functions: The head provides relevant dimensions, whereas the modifier provides candidate features for attribution. According to our model, the interaction of dimensions and features, rather than constituent similarity, guides interpretation. In this study, we empirically contrasted the two models by holding constituent similarity of compounds constant while varying the interaction of modifier feature salience and head dimension relevance. Compounds consisting of a head concept with a relevant dimension for attribution and a modifier with a salient property on that dimension were interpreted by means of property attribution. Other compounds with equivalent constituent similarity, but lacking the high salience-relevance interaction, were not interpreted by means of attribution. The interactive property attribution model more accurately predicted interpretation of noun-noun compounds.
\end{abstract}

How do people understand noun-noun compounds such as mushroom cloud and mushroom sauce? Solving this problem is crucial to a full account of language comprehension (Gagne \& Shoben, 1997; Gerrig \& Murphy, 1992; Springer \& Murphy, 1992) and bears importantly on theories of concept representation (Cohen \& Murphy, 1984; Franks, 1995; Hampton, 1987, 1988; Kamp \& Partee, 1995; Markman \& Wisniewski, 1997; Medin \& Shoben, 1988; Murphy, 1988, 1990; Rips, 1995; Smith \& Osherson, 1984; Smith, Osherson, Rips, \& Keane, 1988). One way to address the question of comprehension is to investigate how such nominal compounds are interpreted. By examining interpretations of combined concepts, we may infer the mental process that yielded those interpretations.

Wisniewski (1996, 1997; Wisniewski \& Love, 1998) has demonstrated that most interpretations may be categorized as either property or relation interpretations. ${ }^{1}$ In property interpretation, a property of the modifier is attributed to the head concept. A mushroom cloud, for instance, is a cloud shaped like a mushroom. The entire modifier concept (mushroom) is not part of the interpretation; instead, only a subset of its features (in this case, its shape) becomes part of the interpretation. In relation interpretation, the compound is interpreted in terms of a relationship between the modifier and head. For example, mushroom sauce is a sauce made with mushrooms. Property interpre-

This research was supported by an NSF Graduate Research Fellowship to the first author and by NSF Grant SBR-9712601 to Princeton University, S. Glucksberg, Principal Investigator. We thank Yevgeniya Goldvarg, James Hampton, Philip Johnson-Laird, Eli Massar, Matthew McGlone, Mary R. Newsome, Lisa Torreano, and anonymous reviewers for their comments. Correspondence should be addressed to Z. Estes, Department of Psychology, Green Hall, Princeton University, Princeton, NJ 08544-1010 (e-mail: zcestes@princeton.edu). tation is the primary focus of this paper. How do people generate such interpretations?

Wisniewski $(1996,1997)$ has proposed an alignmentand-comparison model of how people interpret nounnoun compounds. His model, like many others (e.g., those of Cohen \& Murphy, 1984; Gagne \& Shoben, 1997; Murphy, 1988; and Smith, Osherson, Rips, \& Keane, 1988), assumes a schema representation wherein concepts are represented in terms of dimensions and values (see Minsky, 1975; Rumelhart, 1980). For example, the concept crow has a COLOR dimension that contains the value "black." Extending Gentner's (1983) structure-mapping model of analogy and metaphor comprehension, Wisniewski suggests that in order to comprehend a combined concept, the schemas of the two constituent concepts are initially aligned so that the dimensions of one constituent are put into correspondence with analogous dimensions of the other constituent. Once the dimensions are aligned, the features of the two concepts are compared. This alignmentand-comparison process can be illustrated with the combination car truck. In the alignment stage, dimensions such as the number of wheels, doors, and seats are aligned. This alignment permits feature comparisons, from which commonalities and alignable differences may emerge: Both cars and trucks typically have four wheels (a commonality), but cars typically have four doors and trucks have only two, and cars can seat five people, whereas trucks usually seat two (alignable differences). From these alignable differences, one could derive the interpretation that a car truck is a truck that has four doors and seats five people.

Alignable differences are necessary for property interpretation, because they indicate what property to attribute and to what dimension it should be attributed (Wisniewski, 1997). Because people are more likely to find alignable differences for combined concepts with similar 
constituents than for those with dissimilar constituents (Gentner \& Markman, 1994), it follows that property interpretation is more likely to occur when the constituents of a combination are similar. Dissimilar combinations, such as yarn truck, have differences, too, but these differences tend to be nonalignable; their schemas cannot be put coherently into correspondence. Thus, because property interpretation requires alignable differences, and the differences of dissimilar combinations tend to be nonalignable, property interpretation is unlikely to occur when combined concepts have dissimilar constituents. A yarn truck is not likely to be a truck that has properties of yarn, but one that transports yarn. In this way, constituent similarity is claimed to predict interpretation type (Wisniewski, 1996, 1997; Wisniewski \& Markman, 1993).

To test this hypothesis, Wisniewski (1996) examined people's interpretations of similar (e.g., shark piranha) and dissimilar (e.g., shark coconut) combined concepts. As predicted by the alignment-and-comparison model, similar combinations resulted in far more property interpretations $(72 \%)$ than relation interpretations $(7 \%)$. The interpretation of dissimilar combinations, however, was less clear. Nearly half ( $48 \%$ ) of the dissimilar combined concepts were understood by property interpretation. These data suggest that constituent similarity may not be necessary for property interpretation.

Other data also suggest that constituent similarity may not be sufficient for property interpretation. Goldvarg and Glucksberg (1998) asked people to interpret noun-noun compounds that consisted of modifier and head nouns that, when presented in the form "X is a Y," are apt and comprehensible metaphors (e.g., shark lawyer for my lawyer is a shark). Such combinations were comprehended primarily by means of property interpretation, despite the dissimilarity of their constituents. It appears, then, that high constituent similarity is neither necessary nor sufficient for property attribution to occur in noun-noun combinations.

We offer, as an alternative to the alignment-andcomparison model, an extension of the interactive property attribution model of metaphor comprehension (Glucksberg \& Keysar, 1990; Glucksberg, McGlone, \& Manfredi, 1997) to the domain of concept combination. Assuming the same schema system of representation, we propose that the modifier and the head play different, but equally important, roles: The head provides relevant dimensions, whereas the modifier provides candidate properties for attribution. For example, in the combination shark lawyer, the head concept lawyer provides relevant dimensions for attribution (e.g., TEMPERAMENT, COMPETENCE, COST, etc.), and the modifier shark provides salient candidate properties (e.g., "predatory," "aggressive," and "vicious") that can be attributed. We propose in the interactive property attribution model that, instead of exhaustively aligning the dimensions and comparing the features of the two concepts, people align the relevant dimensions of the head with salient proper- ties of the modifier. According to our model, it is not constituent similarity, but rather the interaction of dimensions and features, that guides interpretation.

This model seems intuitive and parsimonious for such combined concepts as zebra clam. The modifier provides the salient feature, "black and white striped," which fills the COLOR dimension in the head concept. That zebras have hooves and that clams live in the ocean need not be involved in the immediate interpretation process, as alignment-and-comparison models suppose. In fact, when the modifier noun makes available one of its salient features, what begins as noun-noun combination may then proceed in a manner akin to Smith et al.'s (1988) model of adjective-noun combination, by a slot-filler process.

Property interpretation is interactive also in that dimensions and features may become more or less relevant or salient, depending on the concept with which they are combined. That is, a salient feature of a modifier may increase or even introduce the relevance of a dimension in the head concept, and vice versa. For instance, NUMBER OF LEGS is not a particularly relevant dimension of table, since almost all tables have four legs. However, that dimension becomes relevant in the combination octopus table, when interpreted as a table with eight legs. This demonstrates that an extremely high salience or relevance of one constituent in a combination may compensate for a lower relevance or salience in the other constituent. Although such context-dependent salience and relevance are important, in the present investigation we are more concerned with a context-independent (cf. Barsalou, 1982) sense of interaction of modifier feature salience and head dimension relevance. That is, we ask what it is about the individual concepts that leads people to interpret them as such when combined. ${ }^{2}$

To discriminate between the two models, we held the constituent similarity of nominal compounds constant, while manipulating the relationship between the modifier and the head nouns. When a compound consists of a head with a relevant dimension for attribution and a modifier with a salient property on that dimension, we predict that people will produce property interpretations. Other compounds not having this relationship between head dimension relevance and modifier property salience, but with equivalent constituent similarity, will result in relation interpretations. Proponents of the alignment-and-comparison model suppose that constituent similarity guides interpretation, and they therefore predict that combined concepts of equal constituent similarity will be interpreted by property attribution an approximately equal proportion of the time.

\section{SIMILARITY RATING PRETEST}

\section{Method}

Participants. Fourteen Princeton University undergraduate students participated in a similarity rating pretest for partial course 
credit. No student participated in more than one part of the present study, and all were native speakers of American English.

Materials and Procedure. Twenty-five triads of novel combined concepts were created. For the high-salience, high-relevance (HH) compounds, we selected modifiers with highly salient features and heads for which those features would be relevant (e.g., feather luggage). For example, "light" is a salient property of the modifier feather, and WEIGHT is a relevant dimension of the head luggage. As a control, each of these constituents was also paired with another concept. Gagne and Shoben (1997) noted that many concepts have particular relations associated with them, and that people have implicit knowledge of the relative frequencies of these relations. For example, the modifier feather might frequently yield an " $\mathrm{X}$ is light" interpretation, and this could guide interpretation of feather $X$ as "an X that is light," regardless of what X may be. To control for this possibility, we included a high-salience, low-relevance condition (HL) in which the head did not have a dimension that was relevant to the salient properties of the modifier. To illustrate, although "light" is a salient property of feather, the WEIGHT dimension is not relevant to the head storage in the compound feather storage.

Similarly, many concepts have particular dimensions that may invite property attributions from their modifiers. A relevant dimension of luggage in most contexts is WEIGHT, and so the head luggage may receive property attribution on this dimension, regardless of the particular modifier. The low-salience, high-relevance condition $(\mathrm{LH})$ was intended to control for this possibility. This condition consisted of compounds in which the modifier did not have a salient feature that was relevant for that head (e.g., cotton luggage). For instance although the WEIGHT dimension is relevant for the head luggage, the modifier cotton does not have a salient feature on that dimension.

We selected 100 noun concepts to generate 75 combined concepts that met these criteria. Each triad of compounds ( $\mathrm{HH}, \mathrm{HL}$, and $\mathrm{LH})$ included four nouns: For instance, the concepts feather, cotton, luggage, and storage were used to generate feather luggage, feather storage, and cotton luggage. Participants completed a similarityrating task in which five pairs within each triad were rated. The pairwise similarity of the constituents of all 3 combined concepts of each triad was rated, as was the similarity of the two modifiers and the similarity of the two heads (to encourage full use of the scale). For example, students rated the similarity of feather to lug gage, feather to storage, cotton to luggage, feather to cotton, and luggage to storage. This resulted in 125 similarity judgments for each participant. The order of comparison pairs and the order of the constituents in the comparison pairs were randomized. The scale ranged from 0 (very dissimilar) to 6 (very similar).

\section{Results}

Similarity ratings were obtained for the items in all 25 triads. Five triads were discarded because their constituents did not meet the criteria for either modifier feature salience or head dimension relevance (see the attribute/ question generation task below). Accordingly, we report only the similarity rating data for the constituents used in the experiment proper. Mean similarities for the experimental items ranged from .14 to 3.07 . For the $\mathrm{HH}, \mathrm{HL}$, and LH compound types, the mean similarity ratings (and $S D \mathrm{~s}$ ) were $1.49(.97), 1.28(1.04)$, and $1.57(1.05)$, respectively. ${ }^{3}$ As expected, an analysis of variance (ANOVA) with items as a random factor yielded no reliable difference in constituent similarity across the three compound types $[F(2,72)=$ $\left..54, M S_{\mathrm{e}}=.57, p>.5\right]$. The mean constituent similarities of the three compound types thus did not differ significantly from one another.

\section{ATTRIBUTE/QUESTION GENERATION TASK}

\section{Method}

Participants. Fifteen undergraduate students participated for partial course credit.

Materials and Procedure. The individual constituents (e.g., feather and luggage) were partitioned into a list of modifiers and a separate list of heads. So that we could evaluate the salience of the features of the modifier concepts, participants were instructed to "list the first few features that come to mind" for each of the $50 \mathrm{mod}-$ ifier concepts in the attribute listing task. The order of the concepts was random within the list. The participants listed attributes in a booklet, with ample space for responses.

The question generation task was not as straightforward. Murphy (1990) discovered that people have difficulty with the notion of relevance as it pertains to dimensions. For one thing, the difference between salience and relevance is not obvious. To see that salience and relevance are theoretically independent constructs, consider the concept crayon. COLOR is clearly a relevant dimension of crayon, though that dimension need not hold any particular default value. The dimension is thus relevant, though no salient feature is instantiated. This theoretical dissociability of feature salience and dimension relevance suggests different procedures to determine salience and relevance. Since relevance concerns dimensions, not features, a simple feature-listing task is an inappropriate measure of relevance. A more appropriate measure was used by Glucksberg et al. (1997), who had people list questions that would distinguish one instance of a concept from another. For instance, the color of a given crayon is informative for distinguishing it from other crayons. Thus, the question "What color is it?" is a relevant one for crayon, which, in turn, implies that COLOR is a relevant dimension. We adopted this question-listing task as our measure of dimension relevance. Our participants listed questions about each of the 50 head concepts. The order of the concepts was again random within the response booklet, and no concept appeared more than once. Seven participants completed the attribute-listing task before proceeding to the question-listing task; 8 completed the two tasks in the reverse order.

\section{Results}

Five triads for which feature-question generation did not match the desired criteria were discarded, leaving 20 triads with the appropriate characteristics. Each triad consisted of four concepts: $\mathrm{H}$ and $\mathrm{L}$ modifiers and $\mathrm{H}$ and $\mathrm{L}$ heads. Across all experimental items, the mean proportion of participants who listed the expected salient feature was .90 (median, .93) for the $\mathrm{H}$ modifiers and .35 (median, .25) for the L modifiers. To illustrate, for the $\mathrm{H}$ modifier feather, $90 \%$ of students listed "light" in the attribute listing task, but only $35 \%$ listed "light" for the $\mathrm{L}$ modifier cotton. This difference in salience between $\mathrm{H}$ and $\mathrm{L}$ modifiers was significant $[t(38)=6.34, p<.001]$, using a paired $t$ test across items. The mean proportion of participants who listed the relevant dimension for the $\mathrm{H}$ heads was .42 (median, .40) and for the L heads only .20 (median, .04). For example, the WEIGHT dimension was listed by $42 \%$ of participants for the $\mathrm{H}$ head luggage, but by only $20 \%$ for the L head storage. This relevance difference was reliable $[t(38)=2.23, p<.05]$.

To recapitulate, according to the interactive property attribution model, $\mathrm{HH}$ compounds will produce more property interpretations than will either $\mathrm{HL}$ or $\mathrm{LH}$ compounds. For example, because "light" is a salient feature 
of feather and WEIGHT is relevant to luggage, we expect property interpretations for feather luggage. But because WEIGHT is not as relevant to storage, we do not expect as many property interpretations for feather storage. Similarly, although WEIGHT is relevant to the head luggage, we expect few property interpretations for cotton luggage because "light" is not a salient feature of the modifier cotton. The alignment-and-comparison model predicts no difference in property attribution between the three compound types because they do not differ reliably in constituent similarity.

\section{INTERPRETATION TASK}

\section{Method}

Participants. Thirty-nine undergraduate students participated for partial course credit.

Materials and Procedure. Three lists of combined concepts were constructed in such a way that no list contained the same concept more than once and each list contained approximately equal numbers of combined concepts of each compound type. Each list consisted of 20 combined concepts. The order of the combined concepts was random within each list. Each list was completed by 13 participants. The participants were instructed to write a likely interpretation of each combined concept.

\section{Results}

An author and one independent rater who was blind to the hypothesis judged each interpretation as property interpretation, relation interpretation, or other. An interpretation was scored as property interpretation only if it matched the predicted interpretation (e.g., "luggage that is light" for feather luggage). ${ }^{4}$ Interrater reliability was $93 \%$, and discrepancies were resolved by discussion. The proportion of property interpretations served as the dependent measure. These proportions and a summary of the rating task data are provided in Table 1.

ANOVAs across subjects and items indicated that list had no reliable effect (all $p \mathrm{~s}>.15$ ), and so the data were pooled across lists. Two one-way ANOVAs were performed: one with subjects $\left(F_{\mathrm{S}}\right)$ and one with items $\left(F_{\mathrm{I}}\right)$ as a random factor. $\mathrm{HH}$ combined concepts were understood by property interpretation $79 \%$ of the time, whereas $\mathrm{HL}$ and $\mathrm{LH}$ compounds elicited property interpretations only $23 \%$ and $16 \%$ of the time, respectively. As predicted by the interactive property attribution model, this difference in property interpretation was reliable $\left[F_{\mathrm{S}}(2,76)=179.15\right.$, $p<.001$, and $\left.F_{\mathrm{I}}(2,57)=52.8, p<.001\right]$. Paired comparisons revealed that the $\mathrm{HH}$ compounds produced reliably more property interpretations than did either the $\mathrm{HL}$ or the LH compounds, whereas the HL and LH compounds did not differ from one another (Tukey's HSD, $p<.05$ ).

The alignment-and-comparison model cannot explain these findings, on two accounts. First, if two different combined concepts are equivalent in constituent similarity, they should result in approximately equivalent proportions of property interpretation. This did not occur. However, it might be that constituent similarity predicts property interpretation within but not across compound types. Within each compound type ( $\mathrm{HH}, \mathrm{HL}$, and $\mathrm{LH})$, different items have different constituent similarities and different proportions of property interpretation, and these within-group differences in similarity might be correlated with the within-group differences in property interpretation. This was not the case: Constituent similarity was not reliably correlated with proportion of property interpretation within any of the three compound types (all $r \mathrm{~s}<.35$ ). Thus, constituent similarity cannot account for differences in proportions of property interpretation across or within compound types. The second reason that these data are problematic is that the alignment-and-comparison model predicts that dissimilar constituents, when combined, will tend to result in relation interpretation. But in fact, a high proportion (.79) of dissimilar combined concepts (mean similarity rating $=1.49$ on a scale of $0-6$, in which 0 is very dissimilar) were comprehended by means of property interpretation in the $\mathrm{HH}$ condition.

The interaction of feature salience and dimension relevance reliably predicted interpretation type. Interpretation type cannot be attributed to the nature of either constituent alone, because any given constituent resulted in one interpretation type in one condition and a different interpretation type in another. That is, feather and luggage did produce property interpretations in feather luggage, but did not produce property interpretations in feather storage or cotton luggage. Thus, neither the modifier nor the head alone determined interpretation type. Rather, modifiers and heads were used interactively to determine interpretation type.

Table 1

Examples, Similarity, and Mean Proportions of Salience, Relevance, and Property Interpretations by Compound Type

\begin{tabular}{cccccc}
\hline $\begin{array}{c}\text { Compound } \\
\text { Type }\end{array}$ & Example & $\begin{array}{c}\text { Constituent } \\
\text { Similarity }\end{array}$ & $\begin{array}{c}\text { Feature } \\
\text { Salience }\end{array}$ & $\begin{array}{c}\text { Dimension } \\
\text { Relevance }\end{array}$ & $\begin{array}{c}\text { Property } \\
\text { Interpretation }\end{array}$ \\
\hline HH & feather luggage & 1.49 & .90 & .42 & .79 \\
HL & feather storage & 1.28 & .90 & .20 & .23 \\
LH & cotton luggage & 1.57 & .35 & .42 & .16 \\
\hline
\end{tabular}

Note- $\mathrm{HH}$, high salience, high relevance; HL, high salience, low relevance; $\mathrm{LH}$, low salience, high relevance. Salience is the proportion of participants who listed a particular property of the modifier in the attribute listing task, and relevance is the proportion who listed that respective dimension for the head in the question generation task. 


\section{DISCUSSION}

We have addressed the question of how people understand nominal compounds. One model of this process, the alignment-and-comparison model, suggests that the schemas of the two nouns are aligned and then the features of the concepts are matched. The similarity of the constituents is central to this model, because similar constituents are easily aligned and alignment allows property interpretation. However, earlier findings suggested that constituent similarity is neither necessary nor sufficient for property interpretation. We proposed an interactive property attribution model wherein the modifier and head concepts have different functions. We proposed that people do not exhaustively compare the features of the two constituents; we suggested that the head concept provides relevant dimensions, and that the modifier provides salient features for attribution.

We empirically contrasted the alignment-and-comparison model with the interactive property attribution model of concept combination by holding constituent similarity constant while varying the interaction of modifier feature salience and head dimension relevance. This saliencerelevance interaction was greater for $\mathrm{HH}$ compounds than for HL and LH compounds. HH compounds were understood by means of property interpretation more frequently than were either HL or LH compounds; the latter two compound types did not differ from each other in the frequency of property interpretations. Our results thus supported the interactive property attribution model.

By virtue of its specificity, the salience-relevance interaction may also be a more fruitful predictor of interpretation than is constituent similarity. Constituent similarity does not inform one of the specific content of a property interpretation. In contrast, the interactive property attribution model provides a principled basis on which one can predict the precise property that will be attributed, not just that some property of the modifier will be attributed to some alignably different dimension in the head concept.

Bock and Clifton (1998) report corroborative findings of the role of salience in concept combination. They too found that a salient feature of a modifier may drive interpretation and lead to property attribution. However, they did not incorporate into their investigation the relevance of dimensions of head concepts.

Similarly, Costello and Keane (1997), in their constraint satisfaction model of concept combination, argue that properties diagnostic of a modifier concept are attributed to the head concept. For example, a cactus fish is more likely to be interpreted, they say, as a prickly fish than as a green fish because "prickly" is more diagnostic than is "green" of cactus. This idea of diagnosticity is similar to our idea of modifier feature salience, but it differs in one important respect. Reliance on diagnosticity for attribution seems to us too constrained. Which features of a concept are diagnostic is a fairly fixed issue; "prickly" will be a diagnostic feature of cactus, regardless of context. This seems to predict a context-insensitive attribu- tion process. However, our broader notion of salience subsumes diagnosticity as one potential determinant of which property to attribute and also accommodates the influence of context, especially head dimension relevance. A cactus crayon might just be a green crayon, despite the diagnosticity of "prickly" for cactus.

Glucksberg's (Glucksberg \& Keysar, 1990; Glucksberg et al., 1997) interactive model of metaphor comprehension thus seems applicable to the comprehension of attributive noun-noun combinations. However, our analysis is not without limitations. Because of our focus on property interpretation, we have not addressed important questions about relation interpretation. One question of recent interest in the literature is whether one interpretation type is primary: Is property interpretation attempted only after relation interpretation fails $?^{5}$ This question presupposes that relation and property interpretations arise from distinct processes. In support of this, Wisniewski (1996) observed that property interpretation and relation interpretation differ in that the former entails the construal of the modifier as only a subset of its features, whereas the latter requires no such construal. However, we note that the various relations (see, e.g., Levi, 1978) also differ from one another, but that these differences are not taken to indicate separate cognitive processes for each different relation. Differences in representation need not entail differences in process.

A parsimonious alternative is a unitary model in which schemas consist of dimensions for both features and relations. This idea of a unitary model of interpretation processes is consistent with the findings of Gagne and Shoben (1997). Just as modifier concepts have salient (or, in their terms, frequent) relations associated with them, modifier concepts also have salient features associated with them. For instance, the MADE OF relation is salient for the modifier chocolate (e.g., chocolate bunny), and the property of black and white stripes is salient for $z e$ bra (e.g., zebra clam). Furthermore, the relevant dimensions of head concepts may be either relational or featural. For example, the relational dimension CONTAINS is relevant for the head concept box (e.g.,pasta box), whereas the featural dimension COLOR is relevant for crayon (e.g., canary crayon). Such a unitary representation allows a single slot-filler process, rather than distinct slot-filler and alignment-and-comparison processes (see, e.g., Wisniewski, 1997), to account for both relation and property interpretations (see Sifonis \& Ward, 1998, for a similar argument from the structural alignment perspective).

\section{REFERENCES}

Barsalou, L. W. (1982). Context-independent and context-dependent information in concepts. Memory \& Cognition, 10, 82-93.

BoCK, J. S., \& CLIFTON, C. (1998). The role of salience in conceptual combination. In M. A. Gernsbacher \& S. J. Derry (Eds.), Proceedings of the Twentieth Annual Conference of the Cognitive Science Society (p. 1203). Mahwah, NJ: Erlbaum.

Cohen, B., \& Murphy, G. L. (1984). Models of concepts. Cognitive Science, 8, 27-58.

Costello, F., \& Keane, M. T. (1997). Polysemy in conceptual combination: Testing the constraint theory of combination. In M. G. Shafto 
\& P. Langley (Eds.), Proceedings of the Nineteenth Annual Conference of the Cognitive Science Society (pp. 137-142). Hillsdale, NJ Erlbaum.

Franks, B. (1995). Sense generation: A "quasi-classical" approach to concepts and concept combination. Cognitive Science, 19, 441-505.

GAGNE, C. L., \& SHobEN, E. J. (1997). Influence of thematic relation on the comprehension of modifier-noun combinations. Journal of $E x$ perimental Psychology: Learning, Memory, \& Cognition, 23, 71-87.

GENTNER, D. (1983). Structure-mapping: A theoretical framework for analogy. Cognitive Science, 7, 155-170.

GentNer, D., \& MARKMAN, A. B. (1994). Structural alignment in comparison: No difference without similarity. Psychological Science, 5 , $152-158$.

Gerrig, R. J., \& MurPhy, G. L. (1992). Contextual influences on the comprehension of complex concepts. Language \& Cognitive Processes, 7, 205-230.

GluCKSBERG, S., \& KeYSAR, B. (1990). Understanding metaphoric comparisons: Beyond similarity. Psychological Review, 97, 3-18.

Glucksberg, S., MCGlone, M. S., \& Manfredi, D. (1997). Property attribution in metaphor comprehension. Journal of Memory \& Language, 36, 50-67.

GoldVARG, Y., \& GlucksBerg, S. (1998). Conceptual combinations: The role of similarity. Metaphor \& Symbol, 13, 243-255.

HAMPTON, J. A. (1987). Inheritance of attributes in natural concept conjunctions. Memory \& Cognition, 15, 55-71.

HAMPTON, J. A. (1988). Overextension of conjunctive concepts: Evidence for a unitary model of concept typicality and class inclusion. Journal of Experimental Psychology: Learning, Memory, \& Cognition, 14, 12-32.

KAMP, H., \& PARTEe, B. (1995). Prototype theory and compositionality. Cognition, 57, 129-191.

LEVI, J. N. (1978). The syntax and semantics of complex nominals. New York: Academic Press.

Markman, A. B., \& WiSNIEwSKI, E. J. (1997). Similar and different: The differentiation of basic level categories. Journal of Experimental Psychology: Learning, Memory, \& Cognition, 23, 54-70.

Medin, D. L., \& ShOBEN, E. J. (1988). Context and structure in conceptual combination. Cognitive Psychology, 20, 158-190.

MinsKy, M. (1975). A framework for representing knowledge. In P. H. Winston (Ed.), The psychology of computer vision (pp. 211-277). New York: McGraw-Hill.

MurPHY, G. L. (1988). Comprehending complex concepts. Cognitive Science, 12, 529-562.

MURPHY, G. L. (1990). Noun phrase interpretation and conceptual combination. Journal of Memory \& Language, 29, 259-288.

RiPS, L. J. (1995). The current status of research on concept combination. Mind \& Language, 10, 72-104.

RUMELHART, D. E. (1980). Schemata: The building blocks of cognition. In R. J. Spiro, B. C. Bruce, \& W. F. Brewer (Eds.), Theoretical issues in reading comprehension (pp. 33-58). Hillsdale, NJ: Erlbaum.

SiFONIS, C. M., \& WARD, T. B. (1998). Structural alignment in relational interpretations of conceptual combinations. In M. A. Gernsbacher \& S. J. Derry (Eds.), Proceedings of the Twentieth Annual Conference of the Cognitive Science Society (pp. 968-973). Mahwah, NJ: Erlbaum.
Smith, E. E., \& Osherson, D. N. (1984). Conceptual combination with prototype concepts. Cognitive Science, 8, 337-361.

Smith, E. E., Osherson, D. N., Rips, L. J., \& Keane, M. (1988). Combining prototypes: A selective modification model. Cognitive $S_{c i-}$ ence, 12, 485-527.

SPRINGER, K., \& MURPHY, G. L. (1992). Feature availability in conceptual combination. Psychological Science, 3, 111-117.

WISNIEWSKI, E. J. (1996). Construal and similarity in conceptual combination. Journal of Memory \& Language, 35, 434-453.

WisNiewsKi, E. J. (1997). When concepts combine. Psychonomic Bulletin \& Review, 4, 167-183

WISNIEWSKI, E. J., \& LovE, B.C. (1998). Relations versus properties in conceptual combination. Journal of Memory \& Language, 38, 177-202.

WisNiEWSKI, E. J., \& MARKMAN, A. B. (1993). The role of structural alignment in conceptual combination. In Proceedings of the Fifteenth Annual Conference of the Cognitive Science Society (pp. 1083-1086). Hillsdale, NJ: Erlbaum.

\section{NOTES}

1. Another interpretation type is hybridization, in which the combined concept is interpreted as a cross between the two constituents (see Wisniewski, 1996). This form of interpretation is relatively rare and is not considered in this paper.

2. This investigation of the interaction of feature salience and dimension relevance is intended to be a qualitative demonstration, rather than a quantification of the phenomenon of property interpretation. And further, we do not at this point quantify any differential influence of modifiers and heads, as others have done (e.g., Gagne \& Shoben, 1997).

3. Across all triads, mean similarity ratings were $4.35(.98)$ and 4.10 (1.27) for the two modifiers (e.g., feather and cotton) and the two heads (e.g., luggage and storage) of each triad, respectively.

4. Property interpretations in which a property other than the predicted one was attributed were not scored as property interpretation here. For example, feather luggage as "brown luggage"--when we predicted "light luggage"- -would not be scored as a property interpretation. However, when all property attributions are included, the proportions increase only slightly, to $.85, .28$, and .25 for the $\mathrm{HH}, \mathrm{HL}$, and $\mathrm{LH}$ compound types, respectively. When all property attributions are included in the scoring of property interpretation, the pattern of statistically significant differences is identical to the results reported for the proportions of predicted property interpretation.

5. We have preliminary data that address the issue of primacy. In a sensibility judgment task, participants were presented stimuli matched for familiarity, length, and interpretation agreement. For instance, participants read magnet smile (property interpretation), battle theory (relation interpretation), or casserole rodeo (anomalous), and then indicated whether the combination made sense. If relation interpretation is primary, the response times for combinations interpreted by relations should be shorter than for combinations interpreted by property attribution. Instead, we found no reliable difference between the two interpretation types, which suggest that neither is primary (see also Wisniewski \& Love, 1998). However, these data are preliminary. 
APPENDIX

Stimuli (by Combination Type) Used in Interpretation Task, With Salient Feature and Relevant Dimension for Each Triad

\begin{tabular}{|c|c|c|c|c|}
\hline $\mathrm{HH}$ & HL & LH & $\begin{array}{l}\text { Salient } \\
\text { Feature }\end{array}$ & $\begin{array}{l}\text { Relevant } \\
\text { Dimension }\end{array}$ \\
\hline $\begin{array}{l}\text { zebra bag } \\
\text { skunk trash } \\
\text { turtle walker } \\
\text { porcupine carpet } \\
\text { octopus table } \\
\text { rock bagel } \\
\text { fire drink } \\
\text { mouse car } \\
\text { elephant sail } \\
\text { cherry paint } \\
\text { mirror liquid } \\
\text { ice toe } \\
\text { frog crayon } \\
\text { thunder lecture } \\
\text { blimp chicken } \\
\text { skyscraper tree } \\
\text { marathon minute } \\
\text { fossil executive } \\
\text { dictionary talker } \\
\text { feather luggage }\end{array}$ & $\begin{array}{l}\text { zebra trap } \\
\text { skunk scraps } \\
\text { turtle jumper } \\
\text { porcupine tiles } \\
\text { octopus tray } \\
\text { rock circle } \\
\text { fire spray } \\
\text { mouse truck } \\
\text { elephant flag } \\
\text { cherry grease } \\
\text { mirror cleaner } \\
\text { ice head } \\
\text { frog pen } \\
\text { thunder textbook } \\
\text { blimp eagle } \\
\text { skyscraper shrub } \\
\text { marathon time } \\
\text { fossil controller } \\
\text { dictionary writer } \\
\text { feather storage }\end{array}$ & $\begin{array}{l}\text { donkey bag } \\
\text { worm trash } \\
\text { puppy walker } \\
\text { centipede carpet } \\
\text { parakeet table } \\
\text { nut bagel } \\
\text { stove drink } \\
\text { cat car } \\
\text { dolphin sail } \\
\text { berry paint } \\
\text { metal liquid } \\
\text { snow toe } \\
\text { chimp crayon } \\
\text { applause lecture } \\
\text { plane chicken } \\
\text { building tree } \\
\text { triathlon minute } \\
\text { footprint executive } \\
\text { almanac talker } \\
\text { cotton luggage }\end{array}$ & $\begin{array}{l}\text { striped } \\
\text { smelly } \\
\text { slow } \\
\text { prickly } \\
\text { eight legs } \\
\text { hard } \\
\text { hot } \\
\text { small } \\
\text { large } \\
\text { red } \\
\text { reflective } \\
\text { cold } \\
\text { green } \\
\text { loud } \\
\text { fat } \\
\text { tall } \\
\text { long } \\
\text { old } \\
\text { informational } \\
\text { light }\end{array}$ & $\begin{array}{l}\text { pattern } \\
\text { scent } \\
\text { speed } \\
\text { texture } \\
\text { number of legs } \\
\text { solidity } \\
\text { temperature } \\
\text { size } \\
\text { size } \\
\text { color } \\
\text { appearance } \\
\text { temperature } \\
\text { color } \\
\text { volume } \\
\text { size } \\
\text { height } \\
\text { duration } \\
\text { age } \\
\text { subject } \\
\text { weight }\end{array}$ \\
\hline
\end{tabular}

(Manuscript received March 28, 1997;

revision accepted for publication August 4, 1998.) 